\title{
O BNDES E O ESTÍMULO PRODUTIVO AO AGRONEGÓCIO: O PAPEL HISTÓRICO DO FOMENTO PARA A CRIAÇÃO DE ELOS ENTRE A PRODUÇÃO AGRÁRIA E INDUSTRIAL NO BRASIL
}

\author{
BNDES AND THE INCENTIVE TO AGRIBUSINESS:THE HISTORICAL ROLE OF THE \\ PROMOTION FOR THE CRIATION LINKS BETWEEN AGRICULTURAL \\ AND INDUSTRIAL PRODUCTION IN BRAZIL
}

\section{BNDES Y EL ESTIMULO PRODUCTIVO DEL AGRONEGOCIOS: EL PAPEL HISTÓRICO DEL FOMENTO PARA LA CREACIÓN DE VÍNCULOS ENTRE LA PRODUCCIÓN AGRÍCOLA E INDUSTRIAL EN BRASIL}

\author{
Alessandro Francisco Trindade de Oliveira ${ }^{1}$ \\ https://orcid.org/0000-0001-7692-1023 \\ Marlon Clovis Medeiros ${ }^{2}$ \\ https://orcid.org/0000-0002-4648-6662
}

Submissão: 09/11/2020 / Aceito: 15/02/2021 / Publicado: 31/03/2021.

\begin{abstract}
Resumo
Com base nos estudos sobre o desenvolvimento da produção agropecuária brasileira, buscase aqui uma análise sobre a participação do Banco Nacional de Desenvolvimento Econômico e Social (BNDES) na formação do complexo produtivo e comercial conhecido como agronegócio. Para o desenvolvimento dessa análise, o trabalho foi pautado em uma bibliografia ligada a temática, além da busca de dados e informações em órgãos oficiais e também em entrevista feita diretamente no BNDES. Verificamos que, em sua trajetória, o órgão foi criado com o foco setorial na indústria e na infraestrutura, mas que indiretamente propiciou avanços no desenvolvimento do agronegócio nas primeiras décadas de sua atuação. Também constatamos que, nas décadas recentes, ele foi primordial para o desenvolvimento vários programas de modernização da produção agropecuária e da agroindústria, ajudando a consolidar essas áreas como destaques na economia nacional. Por fim, com a política de desinvestimentos dos últimos anos, notamos uma ameaça ao conjunto do setor, com o comprometimento de políticas importantes de desenvolvimento produtivo no Brasil.
\end{abstract}

Palavras-chave: Agronegócio, Banco de Desenvolvimento, Indústria, BNDES.

\begin{abstract}
Based on studies on the development of Brazilian agricultural production, an analysis of the participation of the National Bank for Economic and Social Development (BNDES) in the formation of the productive and commercial complex known as agribusiness is sought here. For the development of this analysis, the paper was based on a bibliography related to the theme, in addition to the search for data and information in official bodies and also in an

\footnotetext{
${ }^{1}$ Doutorando em Geografia pela Universidade Estadual do Oeste do Paraná (Unioeste) campus Francisco Beltrão/PR. Técnico em Informações Geográficas e Estatísticas no IBGE. E-mail: alessandrogeotr@gmail. ${ }^{2}$ Doutor em Geografia pela Universidade de São Paulo (USP). Professor do curso de graduação e pós-graduação em Geografia da Universidade Estadual do Oeste do Paraná (Unioeste) campus Francisco Beltrão/PR. E-mail: marlonmedeiros@hotmail.com.
} 
interview directly with BNDES. We note that, in its trajectory, the bank was created with a sectorial focus on industry and infrastructure, but that indirectly provided advances in the development of agribusiness in the first decades of its existence. We also found, that in recent decades, it has been essential for the development of several programs to modernize agricultural production and agribusiness, helping to consolidate these areas as highlights in the national economy. Finally, with the divestment policy of the past few years, we noticed a threat to the sector as a whole, with the commitment of important policies for productive development in Brazil.

Keywords: Agribusiness, Development Bank, Manufactures, BNDES.

\section{Resumen}

A partir de estudios sobre el desarrollo de la producción agrícola brasileña, se busca aquí un análisis de la participación del Banco Nacional de Desarrollo Económico y Social (BNDES) en la formación del complejo productivo y comercial conocido como agronegocio. Para el desarrollo de este análisis, el estudio se basó en una bibliografía relacionada con el tema, además de la búsqueda de datos e información en organismos oficiales y también en una entrevista realizada directamente en BNDES. Encontramos que, en su trayectoria, el organismo fue creado con un enfoque sectorial de industria e infraestructura, pero que indirectamente brindó avances en el desarrollo de lo agronegocio en las primeras décadas de su desempeño. También constatamos que en las últimas décadas, ha sido fundamental para el desarrollo de varios programas de modernización de la producción agrícola y agroindustrial, contribuyendo a consolidar estas áreas como destaques de la economía nacional. Finalmente, con la política de desinversiones de los últimos años, notamos una amenaza para el sector en su conjunto, con el compromiso de importantes políticas de desarrollo productivo en Brasil.

Palabras chave: Agronegocio, Banco de Desarrollo, Industria, BNDES.

\section{INTRODUÇÃ̃o}

Desde a segunda metade do século XX, o Brasil conta com um importante agente para atuação nas políticas de desenvolvimento: o Banco Nacional de Desenvolvimento Econômico e Social - BNDES. Após a virada do século, essa instituição se tornou central no direcionamento de crédito e pulverização de recursos nos programas de desenvolvimento mais abrangentes, como apresentado em seus editais de financiamento nas áreas de aerodefesa, agropecuária, petróleo e gás, saúde, sustentabilidade, telecomunicações, biomassa e cana-de-açúcar, além de programas que já compunham os serviços de apoio financeiro a empresas, como a atuação em renda variável e demais políticas transversais.

$\mathrm{Na}$ atuação do BNDES junto ao agronegócio ${ }^{3}$, além do crédito concedido às Cooperativas por meio do programa Prodecoop (Programa de desenvolvimento cooperativo

\footnotetext{
${ }^{3} \mathrm{O}$ entendimento de agronegócio trabalho nesse estudo se vincula ao pensamento de Gonçalves (2005), que o pensa como um conjunto de cadeias produtivas agropecuárias mediadas pelo capital financeiro.
} 
para agregação de valor à produção agropecuária), o Banco também foi um importante impulsionador da indústria de equipamentos e máquinas por meio do programa Moderfrota (Programa de modernização da frota de tratores agrícolas e implementos associados e colheitadeiras). Ele também foi responsável por manter os grupos nacionais competitivos frente as multinacionais estrangeiras por meio de financiamentos para fusões e aquisições, que se deram, em parte, com a emissão de títulos de dívida conversíveis em ações, as chamadas debêntures conversíveis, propondo uma associação do Banco aos grupos nacionais, por meio da BNDESPar.

Parte dessas ações foram profundamente criticadas nos anos recentes, sobretudo a política dos "campeões nacionais", que ganhou essa conotação pelos investimentos feitos em grandes empresas para que tivessem capacidade de competição global. As críticas recaíam pouco sobre o processo em si, que elevou determinadas companhias a destaques no mundo, como mostrado em Oliveira (2019), e sim sobre possíveis atos de corrupção envolvendo os recursos provenientes do BNDES.

Assim, aprofundaremos nesse artigo a importância do BNDES enquanto agente do desenvolvimento brasileiro por meio de seus programas, assim como uma instituição fundamental para consolidação do agronegócio nacional e os desafios e ameaças que rondam as políticas de desenvolvimento atuais.

\section{OBJETIVOS E METODOLOGIA}

Diante dos aspectos introdutórios que foram apresentados, salientamos que nossos objetivos principais serão o de analisar como as políticas estatais de fomento criaram e utilizaram a estrutura do BNDES para o desenvolvimento produtivo e como o agronegócio brasileiro foi historicamente beneficiado com tais políticas, mesmo quando o foco principal era o desenvolvimento da infraestrutura e da indústria. Também apresentamos como que recentemente o Banco vem passando por uma reestruturação que ameaça a efetividade de determinadas políticas de crédito, podendo representar um risco para a dinâmica produtiva do agronegócio no futuro.

E para desenvolver nosso estudo, nos pautamos metodologicamente em análises bibliográficas, em uma entrevista realizada junto aos técnicos do BNDES e em dados de estudiosos do tema, do BNDES e do Banco Central do Brasil para que pudéssemos realizar uma construção da história da instituição, assim como entender como sua trajetória esteve 
atrelada às alterações políticas no Brasil e como atua nos anos recentes e como foi uma instituição chave no desenvolvimento produtivo do agronegócio nacional.

\section{A TRAJETÓRIA Do BNDES E SUA IMPORTÂNCIA PARA A ECONOMIA E O AGRONEGóCIO BRASILEIRO}

As políticas desenvolvimentistas adotadas no Brasil a partir da metade do século XX foram as grandes responsáveis por impulsionar nosso setor industrial e ajudaram na construção do edifício econômico brasileiro. O esforço embutido na criação de uma nação industrializada passava, assim como as industrializações clássicas ocorridas em outros países, pela existência de instituições para financiamento produtivo em larga escala com prazos de tempo compatíveis com o amadurecimento da atividade. Ainda era necessário direcionar esses recursos para áreas em que o setor privado não demonstrasse interesse, dado o risco do negócio e o tempo para retorno do crédito, logo, o Banco de Desenvolvimento era uma instituição fundamental para sustentar o arcabouço intervencionista.

Se configurava, assim, o cenário para a criação de parte dos Bancos de Desenvolvimento no mundo chamado subdesenvolvido, que foi acompanhado em sincronia no caso brasileiro, uma vez que foi nesse período que se fundou o Banco Nacional de Desenvolvimento Econômico e Social (BNDES), inicialmente sem o "Social” em seu nome, e sim como Banco Nacional de Desenvolvimento Econômico, em 1952.

A discussão sobre a eficácia dos Bancos de Desenvolvimento e o intervencionismo governamental na promoção do crescimento foi e ainda é motivo de discordâncias teóricas na academia. Consideramos que a atuação do Estado no planejamento e no direcionamento de investimentos foi crucial para o crescimento e consolidação das grandes economias mundiais, não só em períodos de recessão e de reconstrução de guerras, mas também épocas de oportunidades de crescimento e de estabilidade econômica, traçando direcionamentos aos investimentos e, dessa forma, contribuindo para a disseminação dos capitais em diversos ramos produtivos e organizando geograficamente o crescimento dos negócios.

A atuação do Estado promotor do desenvolvimento foi observada, em maior ou menor grau, nas economias avançadas da Europa, América do Norte e também na América Latina, porém, nesse último caso, o avanço se deu com mais consistência somente até os anos 1970. Recentemente a Ásia, com destaque para a China, é a parte do mundo onde o Estado promotor de desenvolvimento tem se sobressaído com destaque. Em muitos locais onde foi 
demonstrado um avanço econômico, um tipo de instituição ganhou destaque, agindo na captação e disseminação de recursos para a produção: o Banco de Desenvolvimento.

Para Petite (2010), esse tipo de instituição aparece com essa nomenclatura somente após a Segunda Guerra Mundial com a criação do Banco Internacional de Reconstrução e Desenvolvimento (BIRD). O autor mostra que, mesmo antes da criação do BIRD, existiam algumas instituições que foram criadas com fins semelhantes aos futuros bancos de desenvolvimento, como o Crédit Mobilier na França, em 1852, o Istituto Mobiliare Italiano, nos anos 1930, o Industrial and Commercial Financeand Finance Corporation for Industry, no Reino Unido em 1945, o Industrial Bank of Japan, em 1902 e a Nacional Financiera no México em 1934.

Mas, segundo Amsden (2009), foram nos países da periferia que o Banco de Desenvolvimento ganhou maior importância, dado que no pós-Segunda Guerra esses países não contaram com a ajuda do Plano Marshall e com um Banco de Reconstrução como ocorreu na Europa e no Japão. Nesse conjunto de países, os que dispunham de um Banco de Desenvolvimento estruturado partiram para investimentos em infraestrutura de transportes e necessidades básicas num primeiro momento, como eletrificação e saneamento. A autora tomou como exemplo o caso mexicano, onde a sua entidade de desenvolvimento estatal, a Nacional Financiera, destinou duas vezes mais crédito de longo prazo que o setor privado na década de 1960. Na Índia, os bancos de desenvolvimento respondiam por larga fatia de investimentos na indústria. Entre as décadas de 1960 e 1970, a Corfo (Corporación de Fomento de la Producción) do Chile respondeu por 55\% de todos os investimentos na indústria e o Banco de Desenvolvimento da Coreia por $45 \%$ na Coreia do Sul.

No Brasil, em meio a outras políticas de participação ativa do Estado na economia no pós-Segunda Guerra, é criado uma instituição exclusiva para fomentar o desenvolvimento produtivo, que ganhou primeiramente a sigla de BNDE (Banco Nacional de Desenvolvimento Econômico). Esse tipo de instituição, no Brasil, surgiu após a criação da CEPAL (Comissão Especial para a América Latina e o Caribe) e da CMBEU (Comissão Mista Brasil-Estados Unidos). Logo, a partir dos anos 1950, esses órgãos apontaram a necessidade dos investimentos em projetos de desenvolvimento nos países periféricos para uma mudança em sua estrutura econômica e social.

Apoiados na concepção das falhas de mercado, a CEPAL e CMBEU se distanciavam do pensamento econômico clássico do mercado autorregulado e viam nas instituições 
nacionais de desenvolvimento a possibilidade da criação de mercados e da geração de empregos, tendo um consenso sobre a necessidade de o Estado traçar as estratégias de desenvolvimento nacional. Para essas instituições, uma situação como a que permitiu a crise dos anos 1930 não deveria ser mais aceita, logo os preceitos que permitiram chegar na situação daquela década, que eram os liberais do laissez-faire, teriam de deixar a esfera dos promotores de políticas de desenvolvimento.

$\mathrm{Na}$ esfera internacional, também foram criados organismos para apoio nas decisões econômicas, que indicavam a atuação governamental como primordial na promoção do desenvolvimento. É nesse contexto que são criados o Fundo Monetário Internacional (FMI) e o Banco Mundial. Já os bancos que atuariam no desenvolvimento interno dos países, teriam a função conforme a descrição a seguir:

$$
\begin{aligned}
& \text { [... As referidas instituições deveriam canalizar recursos } \\
& \text { internacionais e nacionais, em longo prazo, para promover a expansão da } \\
& \text { infraestrutura e da indústria moderna. Para isso, deveriam contar com corpo } \\
& \text { funcional capaz de avaliar projetos com base em técnicas mais avançadas de análise } \\
& \text { e atuar conforme as melhores práticas de contratação financeira. Os BD [Bancos } \\
& \text { de Desenvolvimento] seriam, assim, peças relevantes nos mecanismos de } \\
& \text { direcionamento de crédito a partir dos Estados Nacionais comandariam o } \\
& \text { financiamento em longo prazo de seus programas nacionais de desenvolvimento } \\
& \text { (FILHO; COSTA, 2012, p. 979). }
\end{aligned}
$$

Assim, os países buscariam direcionar os financiamentos dos bancos de desenvolvimento para os nichos de mercado que estavam deficientes em suas economias nacionais. Nos casos da América Latina, essas instituições tiveram atuação ampla, dando foco na infraestrutura de base, apontando uma deficiência nos mercados privados de financiamento de longo prazo. Desde sua criação até os anos 1990 foram raros os grandes investimentos privados e públicos no Brasil que não tiveram o apoio do BNDES. Salientamos que ao longo da história econômica nacional recente, a atuação do BNDES teve diferentes frentes de atuação, que se alteraram conforme as prioridades das políticas de investimentos vigentes.

\section{OS PRIMEIROS ANOS DO BNDES E O APOIO AO DESENVOLVIMENTISMO}

De acordo com Amsden (2009), os critérios para os investimentos do BNDES emergiam de circunstâncias históricas, logo, no começo de sua atuação no Brasil a pauta emergente era a instalação da indústria pesada, dado que da sua criação até o ano de 1967 metade dos fundos do BNDES foram para a indústria siderúrgica. Nesse sentido os 
investimentos destinados ao complexo agroindustrial foram bastante tímidos no início, correspondendo a apenas $3 \%$ dos investimentos totais em sua primeira década de atuação, direcionado para frigoríficos, armazéns, matadouros e silos (BEL FILHO et al, 2012).

Nos dados levantados por Barboza, Furtado e Gabrielli (2018), e publicados pelo próprio BNDES em uma edição de seus textos para discussão, sequer aparecem investimentos direcionados a agropecuária, dados que os investimentos mencionados por Bel Filho (2012) eram encaixados como parte de comércio/serviços ou então elencados como parte da indústria. Isso porque, no entendimento setorial do Banco e dos autores, o investimento na agropecuária seria o realizado diretamente nas propriedades, ou da porteira para dentro, e não os que envolveriam esse setor na forma de um Complexo Agroindustrial, com toda a cadeia que envolve o agronegócio. Mesmo assim os autores nos trazem importantes contribuições ao demonstrarem os direcionamentos dos investimentos em cada período do Banco. Podemos verificar no gráfico 1 para quais áreas se destinaram os recursos provenientes do BNDES nos seus primeiros anos:

\section{Gráfico 1 - Composição setorial dos financiamentos do BNDES entre 1952 e} $1960(\%)$

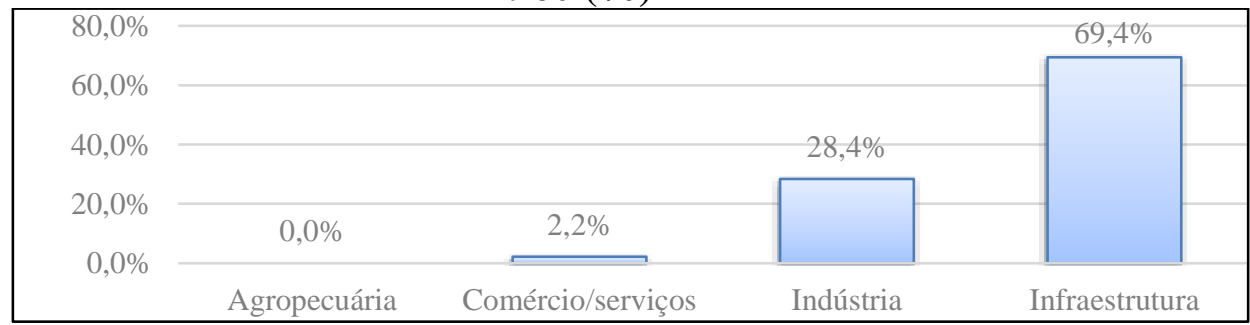

Fonte: Barboza, Furtado e Gabrielli (2018, p.11).

Além da indústria de bens de capital, o Banco também foi importante para a implementação de planos desenvolvimentistas, como o Plano de Metas e os PNDs (Planos Nacionais de Desenvolvimento) durante a ditadura militar e que tinham recursos destinados ao melhoramento da infraestrutura nacional. Em 1964 foi criada a FINAME ${ }^{4}$ (Agência Especial de Financiamento Industrial) para financiamento da indústria de máquinas e equipamentos que, conjuntamente com o SNCR (Sistema Nacional de Crédito Rural) ${ }^{5}$,

\footnotetext{
${ }^{4}$ O BNDES opera como um Banco de primeiro piso, ou seja, repassa recursos para outros bancos (comercias) realizarem as operações junto aos mutuários.

${ }^{5}$ Sistema criado em 1964 para a concessão de crédito governamental para a produção agropecuária. Foi o principal instrumento de crédito rural nas décadas de 1960 e 1970.
} 
proporcionava uma profunda alteração no complexo agropecuário brasileiro, levando a uma maior mecanização das atividades do setor.

Posteriormente, houve uma intensificação na atuação das substituições de importações, acelerada pelos PNDs nos setores de bens de capital e matéria prima básica, e nesse último já incluindo setores mais ligados ao agronegócio como fertilizantes e madeira para papel e celulose. A intensificação das políticas de financiamento da indústria entre os anos 1960 e 1970 foi um pouco mais abrangente, contemplando indústrias complementares a atividade agropecuária com forte atuação na indústria de alimentos, e, nesse sentido, beneficiou estados que sequer dispunham de uma estrutura industrial complexa no Brasil, elevando a participação industrial de $26 \%$ para $33 \%$ do PIB no período.

No trabalho de Flores (2009), por exemplo, é demonstrado como os financiamentos produtivos dos órgãos de fomento ligados ao BNDES foram primordiais para a industrialização do interior paranaense, abrangendo setores como a indústria da madeira e do beneficiamento de produtos de origem agrícola e animal. Especificamente na análise do Sudoeste Paranaense, o autor demonstra como esses aportes na industrialização contribuíram com a desintegração do complexo rural arcaico, e propiciaram o aumento do emprego urbano, induzindo uma maior divisão do trabalho, na qual o campo se especializava nas atividades puramente agropecuárias e as cidades já estabeleciam uma produção industrial relevante.

Nos gráficos 2 e 3 veremos como os aportes na indústria se tornaram majoritários nos anos 1970 e 1980 :

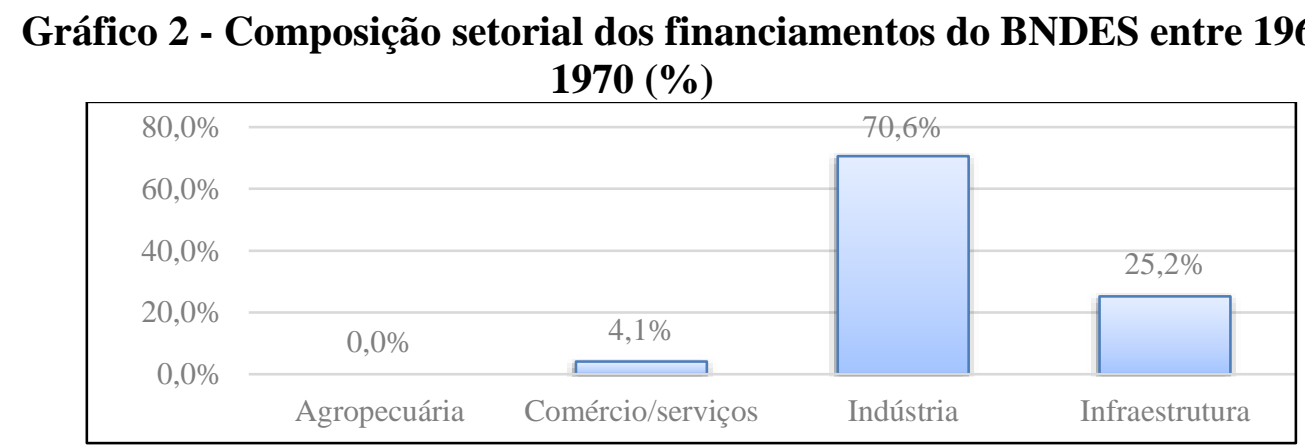

Fonte: Barboza, Furtado e Gabrielli (2018, p.12). 


\section{Gráfico 3 - Composição setorial dos financiamentos do BNDES entre 1971 e $1980(\%)$}

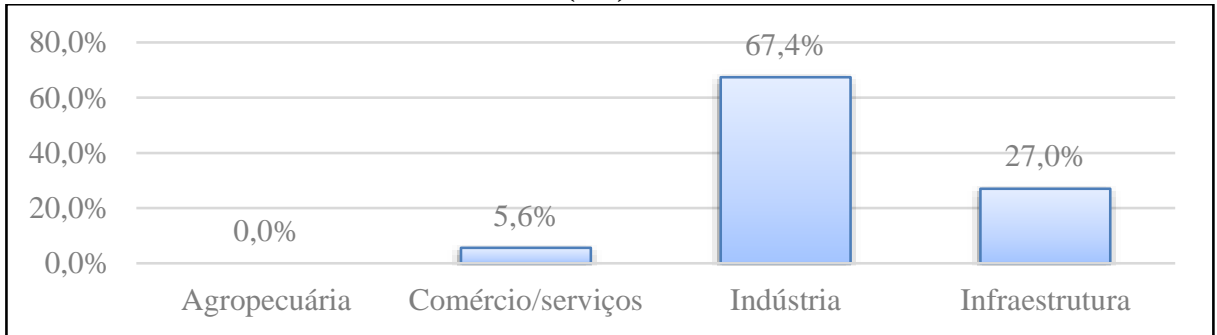

Fonte: Barboza, Furtado e Gabrielli (2018, p.13).

Em 1979, com a crise do petróleo internacional, coube ao BNDES ser o agente principal do programa Proálcool (Programa Brasileiro de Álcool), para diminuir a dependência de petróleo importado a preços elevados. O Banco atuava no financiamento direto das destilarias e indiretamente no financiamento das lavouras de cana-de-açúcar, numa parceria com o Banco do Brasil. Os programas voltados a eletrificação rural e ao melhoramento de estradas também beneficiaram a produção do campo. A agropecuária paulatinamente era entendida como componente da modernização industrial brasileira, e não somente como o setor atrasado da produção nacional. Ainda nos anos 1970 e início dos 1980:

[...] O Banco passou também a oferecer a possibilidade de capitalização das empresas nacionais com participação acionária, com base na criação de três novas subsidiárias: a Mecânica Brasileira S.A. (Embramec), a Insumos Básicos S.A. Financiamento e Participações (Fibase) e a Investimentos Brasileiros S.A. (Ibrasa), em 1982 fundidas para a criação da BNDES Participações (BNDESPar). A filosofia subjacente era a da participação minoritária, com prazo estipulado de desinvestimento, objetivando estimular o desenvolvimento do mercado de capitais. (PAMPLONA, 2011, p.102).

No começo dos anos 1980, foi criada uma instituição subsidiária do Banco de Desenvolvimento, a BNDES Participações (BNDESPar) que agiria com o aporte de capital por meio de investimentos no mercado de renda variável. A BNDESPar tinha como objetivo, além de dar suporte a algumas empresas, o próprio desenvolvimento do mercado de capitais no Brasil, ainda muito incipiente.

Ainda nos anos 1980, em meio à crise, a BNDESPar ganha a missão de sanear empresas como medida compensatória implementada por todo o sistema BNDES. Essas investidas levaram a instituição a ter participação acionária em várias empresas, inclusive majoritária em algumas. Várias dessas seriam privatizadas a partir de 1987, como a Siderbras, Usimec (subsidiária da Usiminas) e a Caraíba Metais (Curralero, 1998). Com isso, ao final da década, o destino dos aportes do BNDES passou a ser, em sua maioria, para grupos 
privados e menos para instituições públicas, chegando a mais de $80 \%$ do valor investido em 1989 para esses tipos de instituições.

\section{Gráfico 4 - Composição setorial dos financiamentos do BNDES entre 1981 e} $1990(\%)$

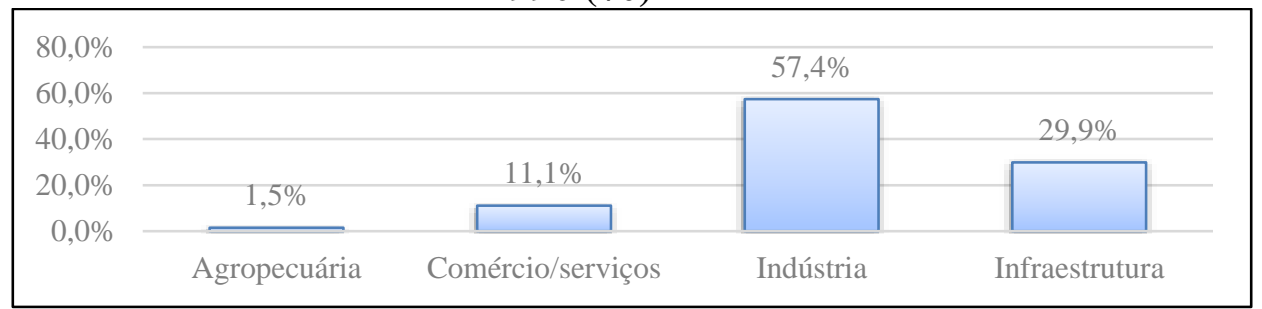

Fonte: Barboza, Furtado e Gabrieli (2018, p.14).

\section{O BNDES NOS ANOS 1990: ATUAÇÃO NA ABERTURA ECONÔMICA E CRIAÇÃO DO PRONAF}

Na década de 1990, o BNDES assumiu um protagonismo nos programas de privatizações e desestatizações, inclusive financiando a compra de diversas estatais. O Banco coordenou, como gestor do Programa Nacional de Desestatização, um grande volume de privatizações, propondo a redução da dívida pública e a obtenção de ganhos de eficiência na produção. Também atuou fornecendo recurso diretamente às Unidades da Federação, para saneamento financeiro de instituições estaduais para posteriormente privatizá-las. Logo, “em 1996, doze [estados] obtiveram adiantamento de recursos da instituição com o compromisso de privatizar e dez deles iniciaram o processo ${ }^{6 "}$ (COSTA, 2011, p. 160). Esse direcionamento afastou, em parte, a atuação do Banco em projetos mais robustos que continuassem a beneficiar o agronegócio nacional.

Em meio a uma política industrial com escassos volumes de recursos e com um cenário político adverso à formação de uma política industrial e de desenvolvimento, o BNDES se encontrava em um caminho difícil, afastando-se de políticas desenvolvimentistas. Apesar disso, o Banco coordenava alguns projetos horizontais de investimento na indústria, como o Proinvest, que foi um programa que não definiu áreas prioritárias para investimento. De acordo com Costa (2011, p. 166):

\section{[...] Suas linhas de ação visavam a eliminação de restrições ao investimento privado nacional e estrangeiro; a redução dos custos tributários dos bens de capital, dos insumos e serviços de infraestrutura; o apoio à importação de tecnologia; o aumento da disponibilidade e redução dos custos do financiamento de longo prazo; e a criação de uma agência de promoção do investimento direto estrangeiro [...].}

${ }^{6}$ Os estados foram os seguintes: Minas Gerais, Paraná, Rio Grande do Sul, Rio de Janeiro, Bahia, Mato Grosso, Mato Grosso do Sul, Sergipe, Rio Grande do Norte, Piauí, Rondônia e Espírito Santo (COSTA, 2011, p. 160). 
Havia uma impulsão de uma guerra fiscal entre os estados brasileiros para alavancagem dos investimentos privados. De 1995 em diante, no início do Plano Real, houve uma substancial elevação dos juros para atração de capital estrangeiro de curto prazo, que em parte, sustentava o Plano. Essa medida, aliada à queda nos preços dos principais produtos agrícolas, teve um efeito danoso ao setor agropecuário, considerando que os financiamentos para o setor, na época, eram operados com taxas de juros pós-fixadas, e assim o endividamento dos produtores aumentava ao passo que suas receitas diminuíam.

A primeira linha de financiamento que buscou reverter o quadro para taxas préfixadas foi o Finame do BNDES que aliado à criação do Pronaf (Programa Nacional de Fortalecimento da Agricultura Familiar), em 1995, passaram a ser formas importantes de aporte de crédito junto aos produtores, que buscavam nos bancos comerciais os recursos, tendo em vista que esses é que atuavam como difusores do dinheiro que vinha do BNDES. Quanto à composição setorial do BNDES, observamos uma interessante elevação do setor agropecuário como destinos de seus aportes, dado os novos programas federais aos quais o Banco estava vinculado:

\section{Gráfico 5 - Composição setorial dos financiamentos do BNDES entre 1991 e $2000(\%)$}

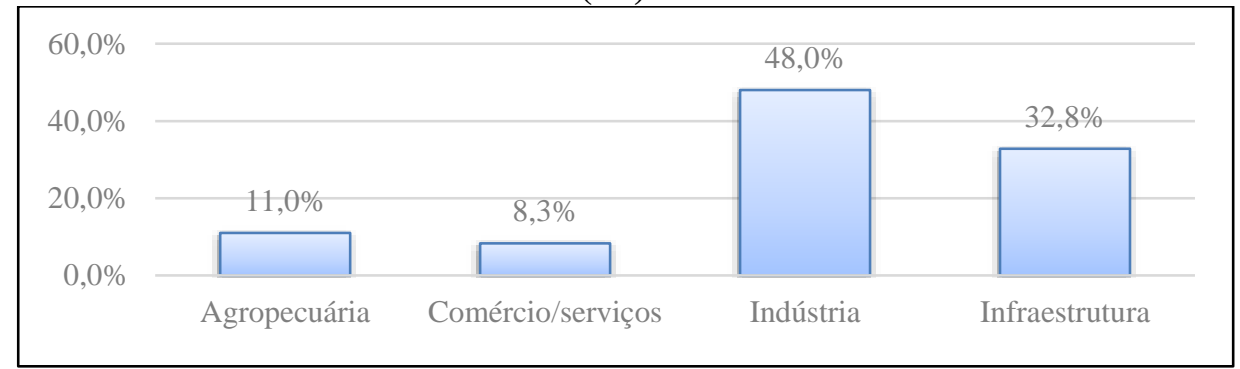

Fonte: Barboza, Furtado e Gabrielli (2018, p.15).

Diante dos dados apresentados até os anos 2000, Barboza, Furtado e Gabrieli (2018) se atentam ao fato do Banco ter, em sua história, fornecido muito mais recursos para a indústria nacional do que para a infraestrutura e assim questionando um pouco a nomenclatura "Desenvolvimento" do nome do BNDES, visto que a infraestrutura teria maior contribuição nesse sentido, para os autores. Porém, relembremos que essa divisão seca entre setores não expõe da maneira mais correta a dinâmica da economia brasileira. Muito do que se destinou a indústria esteve extremamente vinculado ao desenvolvimento de capacidades que abrangiam muito mais do que esse setor. 


\section{O BNDES nos anos 2000: o auxílio na recuperação das cooperativas e a internacionalização dos grandes grupos do agronegócio}

$\mathrm{Na}$ primeira década dos anos 2000, houve uma retomada do sentido desenvolvimentista do BNDES, o que o tornou mais importante perante as políticas de crescimento econômico. No agronegócio, caso desejássemos ter um resumo bastante simplista de como o Banco atuou, poderíamos pensar em dois indicativos principais: a recuperação das cooperativas e a internacionalização dos grandes grupos nacionais. Claro que, além desses dois principais, houve outros direcionamentos dos aportes do Banco no agronegócio, como os feitos na agroindústria ligada ao papel e celulose, açúcar e álcool, mas sem dúvida, os segmentos que foram mencionados ganharam destaque.

A alta dos preços das commodities, sozinha, não explicaria o bom desempenho do agronegócio na década em questão, caso esse segmento não estivesse articulado o suficiente, com uma cadeia de produção, integrada à logística e à agroindústria. Para isso, já em 2001, era liberado um valor recorde para o complexo agroindustrial de $\mathrm{R} \$ 7,4$ bilhões, sendo mais de $60 \%$ desse para a agroindústria (BEL FILHO et al, 2012). Nesse montante operado pelo Banco por meio de seus programas, destacamos os seguintes: o Pronaf, o Moderfrota e os programas destinados às cooperativas (Prodecoop e Procap-Agro).

O Pronaf é destinado a pequenos produtores, com crédito para investimentos e custeio em diversos segmentos, com taxas que variam de acordo com a situação socioeconômica do produtor. O programa cresceu substancialmente ao longo da década de 2000 de modo que em 2011 liberava quase cinco vezes mais recursos que em 2001. O Pronaf foi criado na metade dos anos 1990, mas pouco cumpria de sua missão inicial até os anos 2000, tendo em vista que os valores iniciais de financiamento foram diminuindo de 1995 até 1999, porém nos anos 2000 voltam a crescer, atingindo seu ápice de liberações e de abrangência após 2005.

O Moderfrota iniciou no começo da década de 2000 e foi crescendo de modo que ao final da década liberava, anualmente, 35\% a mais que em 2001. Esse programa, como mencionamos, ajudou a elevar o patamar de mecanização no campo brasileiro, observado 
nos crescimentos quantitativos de tratores e outros tipos de maquinários agrícolas ${ }^{7}$ (BEL FILHO et al, 2012).

Para as cooperativas, inicialmente o BNDES atuou por meio do Programa de Desenvolvimento Cooperativo para Agregação de Valor à Produção Agropecuária, o Prodecoop, incrementando e modernizando os sistemas de mecanização e produção de suas atividades. Esse se tornou o principal programa do Banco de crédito destinado às cooperativas e tinha como objetivo o fornecimento de recursos para a modernização da infraestrutura e dos sistemas de produção e comercialização. O programa iniciou com limites de $\mathrm{R} \$ 20$ milhões por cooperativa em 2003, aumentando esse valor até chegar até $\mathrm{R} \$ 100$ milhões em 2012 com juros a partir de 5,5\% ao ano e prazo de até 12 anos para pagamento. A região que mais foi beneficiada nos aportes dessa linha de financiamento foi a região Sul do Brasil que na primeira década do programa abrangeu mais de $60 \%$ dos financiamentos (PADILHA, 2014).

A outra linha que destacamos e que se destinou às cooperativas agropecuárias foi o Procap-Agro, criado em 2009. Essa linha teve como objetivo manter o fornecimento de crédito, sobretudo capital de giro, após a crise econômica de 2008, na qual se diminuiu consideravelmente a disponibilidade de crédito internacional. Essa resposta do BNDES à demanda das cooperativas, que passariam por dificuldades de aportes de crédito, conseguiu fornecer R\$ 6 bilhões até 2012 dando suporte principalmente às cooperativas do Sul e Sudeste brasileiro.

Os programas destacados até aqui se dirigiam aos setores ligados ao agronegócio brasileiro, mas por meio deles já percebemos como foi a atuação nessas primeiras décadas do século XXI. Houve um novo direcionamento com um novo plano estratégico, voltou-se a pensar no BNDES como uma instituição de fomento de setores estratégicos e que pudesse ajudar num novo ciclo de desenvolvimento. A aparência que se indicava era de uma retomada da articulação do Banco com alguns projetos voltados ao incremento produtivo e também uma busca pela inclusão de novas classes no acesso ao crédito, caso do Pronaf.

Essa mudança em sua forma de atuação levou o BNDES a voltar de forma mais enfática ao apoio às exportações, ao crédito à micro e pequenas empresas e à infraestrutura.

\footnotetext{
${ }^{7}$ Para exemplificar, utilizando os dados dos Censos Agropecuários do IBGE (2007 e 2017), temos que o número de tratores cresceu 49,7\% entre 2007 e 2017, chegando a 407.916 unidades. O número de semeadeiras cresceu $12,41 \%$, o de colheitadeiras $48,34 \%$ e o de adubadeiras $71,21 \%$.
} 
Diante disso, destacamos três políticas essenciais para esse processo: a Política Industrial, Tecnológica e de Comércio Exterior (PITCE), de 2004, o Programa de Aceleração do Crescimento (PAC), de 2007, e a Política de Desenvolvimento Produtivo (PDP), de 2008.

A PITCE teve como legado a instituição de alguns marcos regulatórios e foi base para a criação de algumas linhas de financiamento do BNDES, mas avançou pouco em seus objetivos iniciais, tanto que a PDP foi um complemento da primeira como tentativa de dinamizar setores de maior agregação tecnológica. Em termos de valores absolutos de desembolso, o PAC acabou se sobressaindo, sendo um importante vetor de financiamento da infraestrutura logística, energética, urbana, além de abranger outros setores como a defesa.

Nesse período, outra modificação importante foi a mudança na legislação que definia restrições à concessão de empréstimos ao setor público. Assim, os recursos destinados ao investimento, como um todo, mantiveram-se em elevação até 2008, com um salto nos anos de 2009 e 2010, se correlacionarmos os valores com as porcentagens do PIB brasileiro, e também em valores absolutos. Esse aumento se deu pela Política de Desenvolvimento Produtivo, que teria como propósito alavancar alguns setores da indústria nacional e dar grande impulso às exportações, e também às internacionalizações. Aliado a isso, esse aumento se mostrou como uma importante medida anticíclica, visto que em 2008 se desencadearia o início de uma crise econômica mundial (BASTOS, 2012).

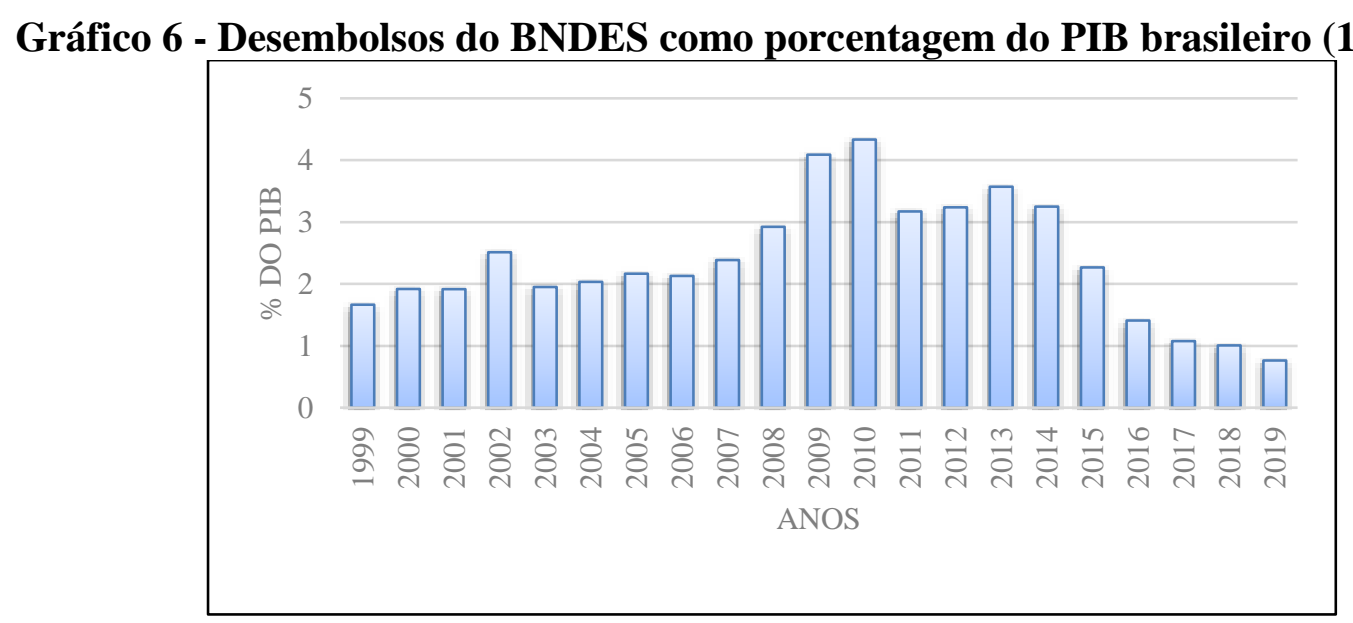

Fonte: BNDES, 2020; e Sistema Gerenciador de Séries Temporais, 2020 - Bacen. Organizado pelo autor.

De 2005 em diante, outro segmento de atuação do BNDES junto ao agronegócio ganhou destaque: as internacionalizações. Esse tipo de incentivo do Banco transcorreu 
principalmente por meio da atuação do BNDESPar, que realizava aportes em algumas empresas por meio da renda variável. As internacionalizações viriam a se encaixar no pilar do incentivo à concorrência externa das empresas brasileiras. Inicialmente elas foram incentivadas para alavancar as exportações brasileiras por meio do programa Exim, do BNDES, que trabalhava com linhas específicas para exportações, mas posteriormente houve uma evolução no entendimento do Banco sobre esse tipo de apoio e a internacionalização passa a transcender a alavancagem das exportações.

Essa evolução se deu com a já citada Política de Desenvolvimento Produtivo (PDP) e dentro dessa política se desenvolveu uma série de prioridades. Dentre essas prioridades, havia a de que, nos setores onde o Brasil é competitivo, deveria se estimular a formação de empresas fortes globalmente no setor. Nesse sentido, alguns grupos do agronegócio já despontavam como empresas com proeminência em exportações e com capacidade produtiva para competição global. Assim, foram feitos significativos aportes no grupo JBS e Marfrig que atualmente são justamente os dois maiores processadores de carne do mundo.

De 2005 até 2012, a empresa JBS realizou 12 aquisições no exterior, sendo essas na América Latina, Estados Unidos e Austrália, ampliando a quantidade de plantas produtivas e também obtendo acesso a mercados não tão acessíveis somente por meio das exportações. Já a Marfrig realizou 15 aquisições internacionais no período compreendido entre 2006 e 2010, a maioria na Argentina e Uruguai, mas também outras de grande importância como a compra da Keystone Foods nos Estados Unidos e da Moy Park no Reino Unido (OLIVEIRA, 2019).

A intenção era que houvesse a possibilidade de agregar valor aos produtos, e também a possibilidade de conhecer melhor os mercados externos tendo acesso direto a eles, ou seja, instalando unidades produtivas no exterior. Assim, a possibilidade de alavancagem dos negócios poderia ser maior, já que muitos mercados possuem restrições à importação de determinados produtos, logo os ganhos com a remessa de lucros das filias para a matriz brasileira mais a possibilidade de agregação de know-how das empresas adquiridas poderia ser favorável ao capitalismo nacional ${ }^{8}$.

Essas aplicações em renda variável exclusivamente para aquisições de outros grupos foram utilizadas em um curto período temporal, sendo pouco observadas após 2011. Em anos

\footnotetext{
${ }^{8}$ Informações contidas na entrevista concedida por Lima, Mendes e Tosta (2014) em visita do autor ao BNDES. 
mais recentes foram duramente criticadas na mídia brasileira, por seu direcionamento a determinados grupos, como se tratasse de uma troca de favores por supostos aportes a campanhas eleitorais. Esse tipo de questionamento é bastante enfatizado por Lazzarini (2011), tanto nas operações de aquisições internacionais, sobretudo as do grupo JBS, quanto nos demais aportes da BNDESPar para expansão interna de empresas de diversos segmentos.

$\mathrm{O}$ viés dito como intervencionista pelo autor, ao se tratar dos aportes em renda variável realizados pelo BNDES, não teve uma sequência de crescimento após as grandes aquisições realizadas pelos frigoríficos. Tivemos sim a proposta para que o Banco agisse no sentido da descapitalização de determinadas empresas de sua carteira.

Os discursos sobre descapitalização do BNDES, privatizações e afastamento do "mal" do Estado sobre os negócios da iniciativa privada foram mais inflados, culminando no atual governo que está batendo recordes históricos de baixos desembolsos do BNDES, que, como visto no gráfico 6, regrediu à patamares dos anos 1990 se for levar em consideração os desembolsos como proporção do PIB. Também está em curso uma operação de revisões/auditorias dos contratos realizados pelo BNDES junto aos grandes grupos nacionais, numa espécie de "abertura de caixa-preta", inclusive com utilização desse termo. Nesse processo, além da auditoria, ocorre o bloqueio de novas operações que se assemelhem às investigadas.

Como síntese, buscamos realizar um quadro para entendermos como o Banco se inseriu na conjuntura produtiva nos principais períodos da história econômica recente brasileira, percebendo como foi importante para a construção do encadeamento produtivo de uma das 10 maiores economias do mundo. 


\begin{tabular}{|c|c|}
\hline Período & Principais ações desempenhadas pelo BNDE - BNDES \\
\hline $1952-1960$ & $\begin{array}{l}\text { Reaparelhamento da malha ferroviária nacional e expansão do programa de eletrificação; } \\
\text { estruturação do setor siderúrgico e execução do plano de metas com investimentos nos setores de } \\
\text { base e consolidação da indústria automobilística. }\end{array}$ \\
\hline $1960-1973$ & $\begin{array}{l}\text { Recursos foram direcionados também para o setor privado nacional com foco em pequenas e médias } \\
\text { empresas; criação da Agência Especial de Financiamento Industrial (FINAME) com objetivo de } \\
\text { crescimento e consolidação da indústria nacional de máquinas e equipamentos. }\end{array}$ \\
\hline $1974-1980$ & $\begin{array}{l}\text { O BNDE ofereceu a possibilidade de capitalização das empresas nacionais com participação } \\
\text { acionária, com base na criação de três novas subsidiárias: a Mecânica Brasileira S.A. (Embramec), a } \\
\text { Insumos Básicos S.A. Financiamento e Participações (Fibase) e a Investimentos Brasileiros S.A } \\
\text { (Ibrasa), em } 1982 \text { fundidas para a criação da BNDES Participações (BNDESPar); sustentação do } \\
\text { crescimento a partir do II PND, em um período recessivo mundial devido à crise internacional do } \\
\text { petróleo por meio de crédito a setores específicos. }\end{array}$ \\
\hline $1980-1988$ & $\begin{array}{l}\text { Destinação de recursos ao então criado FINSOCIAL com objetivo de conter a elevada desigualdade } \\
\text { social gerada no país e acirrada pela crise do início da década; realização de investimentos mais } \\
\text { robustos no setor agropecuário; operação do Programa Nacional do Álcool (PROÁLCOOL) e } \\
\text { financiamento de projetos de infraestrutura urbana. }\end{array}$ \\
\hline $1988-2003$ & $\begin{array}{l}\text { Reforço do papel da indústria privada; aprimoramento do potencial exportador do Brasil } \\
\text { coordenação do Programa Nacional de Desestatização iniciando o financiamento de exportações } \\
\text { apoio ao setor de comércio e serviços. }\end{array}$ \\
\hline $2003-2008$ & $\begin{array}{l}\text { Buscou-se retomar o papel de "Banco de Desenvolvimento"; apoio as exportações de micro e } \\
\text { pequenas empresas e à internacionalizações de grandes empresas; formulação da Política Industrial } \\
\text { Tecnológica e de Comércio Exterior (PITCE); engajamento no Programa de Aceleração do } \\
\text { Crescimento (PAC) e Política de Desenvolvimento Produtivo (PDP). }\end{array}$ \\
\hline $2008-2016$ & $\begin{array}{l}\text { Por conta da crise econômica internacional também foi incumbido ao BNDES o Programa Especial } \\
\text { de Crédito (PEC) para suprir a escassez de crédito no mercado e o Programa de Sustentação do } \\
\text { Investimento (PSI); dá sequência ao financiamento de empresas e ao investimento no país, inclusive } \\
\text { com aporte de recursos do Tesouro Nacional. }\end{array}$ \\
\hline $2016-2020$ & $\begin{array}{l}\text { Pressão pelo aumento da transparência das ações do BNDES; auditoria de casos com supostas } \\
\text { irregularidades (especificamente no envolvimento com a JBS e a Petrobrás); aceleração da venda de } \\
\text { participações do BNDESPar; pagamento de dívida com o Tesouro Brasileiro e auxílio na venda de } \\
\text { empresas estatais estaduais e federais até o ano de } 2023 \mathrm{em} \text { um número mínimo de } 30^{9} \text {. }\end{array}$ \\
\hline
\end{tabular}

Elaborado pelo autor.

\section{CONSIDERAÇÕES FINAIS}

Por meio do estudo apresentado, verificamos que o BNDES foi um dos agentes centrais que ajudaram o Brasil a ter um avanço produtivo que possuiu poucos correspondentes comparativos a nível mundial até os anos 1980, bastante superior as demais experiências latino-americanas e comparável ao que foi observado nas economias mais dinâmicas do mundo. Um país que até a metade do século dependia quase que exclusivamente de exportações primárias e possuía um quadro industrial básico, quase que somente voltado a bens de consumo internos, conseguiu elevar seu complexo produtivo a um patamar de destaque, construindo uma das maiores economias industriais do mundo até os dias de hoje.

\footnotetext{
${ }^{9}$ Conforme informações do plano trienal 2020-2023 disponibilizado no site do Banco.
} 
Esse quadro trouxe impactos significativos para o avanço do agronegócio brasileiro, que passou a ter uma demanda maior, dado o crescimento da população urbana, tanto no fornecimento de bens primários quanto matérias primas para a indústria, sobretudo a de bens de consumo. O avanço da infraestrutura de estradas, ferrovias e armazenagem também permitiu uma interiorização da produção, com a inserção do interior sulista e do Centro-Oeste brasileiro na rede produtiva da agricultura, pecuária e agroindústria. Parte desse aparato governamental usado para o crescimento sofreu com a crise dos anos 1980 e não se recuperou posteriormente, já com a busca de diversos instrumentos privados para os investimentos produtivos, mas que não estavam de acordo com a escala produtiva nacional. Com relação ao agronegócio nacional, esse processo se evidenciou claramente, tendo em vista que os instrumentos privados de financiamento não eram correspondentes com a demanda produtiva nos anos 1990.

Nos anos 2000, o crescimento da demanda internacional por commodities novamente destacou a produção do agronegócio brasileiro. Mas esse segmento não estaria preparado para sua contribuição significativa a balança comercial se não dispusesse de um aparato produtivo de tecnologias aplicadas a produção, transporte e armazenagem constituído. Assim, o desenvolvimento produtivo construindo ao longo da segunda metade do século XX deu um suporte. Evidentemente era preciso mais avanços e uma renovação desses aparatos para que continuássemos como grandes produtores e exportadores mundiais e, nesse sentido, o BNDES voltou a ser proeminente nas políticas de crédito produtivo.

Como discutimos, o Banco atuou como vetor de disseminação de crédito produtivo em diversas frentes. Operou nas linhas de custeio e investimento agropecuários, por meio da pulverização de crédito em instituições como o Banco do Brasil e as cooperativas de crédito, elevando os patamares de utilização de fertilizantes, controladores químicos e maquinários de plantio, colheita, transporte, armazenamento e outros que possibilitaram um incremento na produção.

Nesse sentido, também beneficiou indiretamente uma série de setores industriais que possuem relação com o agronegócio, como os fabricantes de máquinas e insumos e também a indústria de bens de consumo. Corroborando com o processo, muitas cooperativas passavam a se industrializar cada vez mais, com linhas de crédito específicas para melhoramento de suas estruturas e para o processamento dos produtos de seus cooperados. 
Os desembolsos do BNDES, em todas as suas linhas, despencaram para menos de $1 \%$ do PIB em 2019, sendo o menor em toda a série histórica. Esse fato representa um grave risco ao desenvolvimento produtivo, baseando-se na premissa que se deve contrair as políticas produtivas conduzidas pelo Estado no Brasil. A exagerada confiança no setor privado predomina cada vez mais nas políticas econômicas nacionais e o discurso com relação à atuação do BNDES centrasse em auditorias das próprias operações, partindo do princípio de que haveria supostas fraudes e assim se desarticulam as possibilidades de continuidade de determinados tipos de investimento.

Mesmo com a proposta gerada do novo desenvolvimentismo, os paradigmas neoliberais se sobressaíram nas discussões e formulações de políticas econômicas brasileiras do início do século XXI. Sendo essa ainda uma discussão que gera discordância no meio acadêmico, quanto à eficácia de uma ou outra linha econômica, e merece espaço em todos os trabalhos que tratam de nosso desenvolvimento produtivo, pois é central para avançarmos na construção de um entendimento sobre a economia nacional.

Constata-se, com relação à produção brasileira, e mais precisamente ao agronegócio, que esse teve uma internacionalização intensa nos anos recentes, marcada por privatizações e inserção de investidores externos nas empresas brasileiras. Também houve um afastamento do Estado dos papéis centrais de organização e investimento da produção nacional, apesar de sua, ainda, importância estratégica. E assim, um dos mais importantes instrumentos de financiamento, o BNDES, vem tendo sua estrutura desarticulada com os propósitos de crescimentos setoriais e, por consequência, não podendo não mais cumprir o papel para o qual foi criado.

\section{REFERÊNCIAS}

AMSDEN, Alice Hoffenberg. A ascensão do "resto": os desafios ao ocidente de economias com industrialização tardia; tradução de Roger Maioli dos Santos. São Paulo: editora unesp, 2009.

BARBOZA, Ricardo; FURTADO, Maurício; GABRIELLI, Humberto. A atuação histórica do BNDES: o que os dados têm a nos dizer? Rio de Janeiro: Banco Nacional de Desenvolvimento Econômico e Social, 2018. 27 p. (textos para discussão;123).

BASTOS, Valéria D. 2000 - 2010: uma década de apoio à inovação no Brasil. Revista do BNDES, Rio de Janeiro, n 37, 127-176, jun 2012. 
BACEN - BANCO CENTRAL DO BRASIL. Sistema gerador de séries temporais. Disponível em: $<$ https://www.bcb.gov.br>. Acesso em dez. 2020.

BEL FILHO, Egmar Del et al. Apoio do BNDES à agroindústria: retrospectiva e visão de futuro. In: BNDES 60 anos: perspectivas setoriais. Rio de Janeiro: Banco Nacional de Desenvolvimento Econômico e Social, 2012. pp. 88-121.

BNDES - BANCO NACIONAL DE DESENVOLVIMENTO ECONÔMICO E SOCIAL. Evolução dos desembolsos. Disponível em: $<$ https://www.bndes.gov.br/wps/portal/site/home/transparencia/estatisticasdesempenho/desembolsos>. Acesso em dez. 2020.

COSTA, Karen F. Metamorfoses: o papel do BNDES na reordenação da economia brasileira. 2011, 299f. Tese (Doutorado em Ciência Política) - Unicamp, Campinas.

CURRALERO, Cláudia R. B. A atuação do sistema BNDES como instituição financeira de fomento no período 1952/1996. 1998. 165f. Dissertação (Mestrado em economia) Unicamp, Campinas.

FILHO, Ernani T. T; COSTA, Fernando N. BNDES e o financiamento do desenvolvimento. Economia e sociedade, Campinas, v. 21, número especial, p. 975 1009, dez. 2012.

FLORES, Edson Luiz. Industrialização e desenvolvimento do sudoeste do Paraná. 2009. 226f. Dissertação (Mestrado em Geografia) - Unioeste, Francisco Beltrão.

GONÇALVES, José Sidnei. Agricultura sob a égide do capital financeiro: passo rumo ao aprofundamento do desenvolvimento dos agronegócios. Informações Econômicas, São Paulo, v.35, n.4, abr. 2005. pp. 07-35.

IBGE - INSTITUTO BRASILEIRO DE GEOGRAFIA E ESTATÍSTICA. Censo agropecuário 2006. Rio de Janeiro: ibge, 2009.

. Censo agropecuário 2017. Rio de Janeiro: ibge, 2019.

LIMA, Jaldir F.; MENDES, André G. T.; TOSTA, Rodrigo G. R. Entrevista concedida à Alessandro F. T. de Oliveira. Rio de Janeiro, 28 abr. 2014

LAZZARINI, Sérgio G. Capitalismo de laços: os donos do Brasil e suas conexões. Rio de Janeiro: Elsevier, 2011.

OLIVEIRA, Alessandro F. T. A criação de líderes mundiais: uma análise sobre a internacionalização dos conglomerados JBS e Marfrig. In: VIDEIRA, Sandra L. COSTA, Pierre Alves. Dinâmicas Econômicas Contemporâneas: uma perspectiva geográfica. Curitiba: crv, 2019. 
PADILHA, Wilian. O papel do crédito no desenvolvimento das cooperativas agropecuárias. 2014. 229f. Dissertação (Mestrado em Geografia) - Unioeste, Francisco Beltrão.

PAMPLONA, Leonardo de Moura P. BNDES e desenvolvimento do século 21: estado, democracia e sustentabilidade. 2011. 148f. Dissertação (Mestrado em Políticas Públicas) UFRJ, Rio de Janeiro.

PETITE, José Geraldo Rabello. O papel do BNDES no recente processo de internacionalização das empresas brasileiras. 2010. 76f. Monografia (Faculdade de Economia). Unicamp, Campinas. 